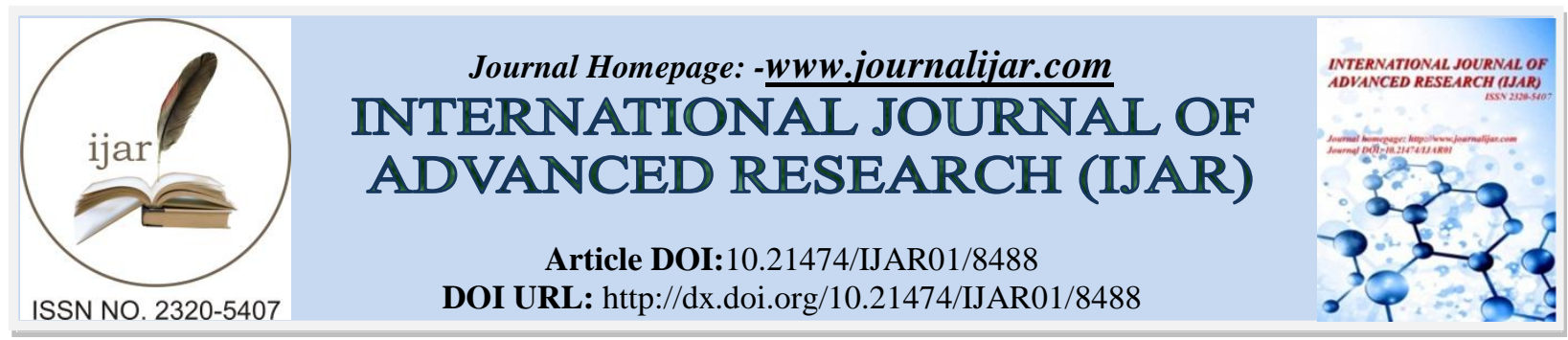

RESEARCH ARTICLE

\title{
PREVALENCE OF SOCIAL ANXIETY DISORDER AMONG SECONDARY SCHOOL STUDENTS IN AL BAHA REGION IN (KSA).
}

\footnotetext{
Abdullah AlSoheimi ${ }^{1}$, Mohamed Abouzed ${ }^{2}$, Ibrahim Dawod ${ }^{3}$, Gebreil Kamal ${ }^{3}$, Abdullah modan ${ }^{2}$, Abdullah hader $^{3}$, Mofareh Zahrani ${ }^{3}$, Fares ali Abdullah al ghamdi ${ }^{4}$, Aedhomoud $^{5}$ and Saed Soliman ${ }^{6}$.

1. Psychiatry consultant inBalgurashi mental hospital .Assistant of the general director for hospitals affairs in ministry of health .Kingdome of Saudi Arabia.

2. Lecturer of psychiatry, AL-AzharUniversity , faculty of medicine ,psychiatry department ,Cairo „Egypt.

3. (Psychiatrist) Balgurashi mental hospital.Kingdome of Saudi Arabia.

4. (psychologist) Balgurashi mental hospital+ medical services in AL Baha directorate of health affairs. medical services in AL Baha directorate of health affairs.Kingdome of Saudi Arabia.

5. (psychologist) Aqiq General hospital.Kingdome of Saudi Arabia.

6. Balgurashi mental hospital. Kingdome of Saudi Arabia.
}

\section{Manuscript Info}

\section{Manuscript History}

Received: 04 December 2018

Final Accepted: 06 January 2019

Published: February 2019

Key words:-

social anxiety ,secondary school.

\begin{abstract}
Background:Social phobia is anxiety disorders manifested by a significant amount of fear in social situations, associated with distress and impaired ability to function in the daily life.

Objective and Methods: The present study aimed at : (1) estimating the prevalence of social anxiety disorder in secondary school students in a geographically defined population, in Baha area using two scales Rewitie scale of social anxiety and severity scale for social anxiety (2) determine risk factor which may be significant .

our survey study covered 6 cities , 31 schools and 1316 students .the sample taken was 1030 students .5 of them didn't complete the study.sotho total number is 1025 .

Result : the total positive sample was $21.8 \%$. there is highly statistically significant association between birth order, place of residenceand social anxiety.

Conclusion:there is a high percentage of secondary school students diagnosed with social anxiety disorder (using the mentioned scales) indicating the importance of the problem in Baha region for further researches behind the causes .
\end{abstract}

Copy Right, IJAR, 2019,. All rights reserved.

\section{Introduction:-}

Social anxiety disorder (previously termed 'social phobia') was formally recognized as a separate phobic disorder in the mid-1960s 1 . The term 'social anxiety disorder' reflects current understanding, including in diagnostic manuals, and is used throughout the guideline. As set out in the International Classification of Diseases, 10th Revision (ICD10) (2) and in the Diagnostic and Statistical Manual of Mental Disorders, 4th Edition Text Revision (DSM-IV-TR) (3)

Corresponding Author:-Abdullah AlSoheimi.

Address:-Psychiatry consultant in Balgurashi mental hospital .Assistant of the general director for hospitals affairs in ministry of health. 


\section{$\underline{\underline{301-305}}$}

There are no UK epidemiological surveys that specifically report data on social anxiety disorder in adults; however, the prevalence of social anxiety disorder has been included in large general population surveys in other western European countries, the US and Australia. Prevalence estimates vary, with much of the variability probably being due to differences in the instruments used to ascertain diagnosis. However, it is clear that social anxiety disorder is one of the most common of all the anxiety disorders. Lifetime prevalence rates of up to $12 \%$ have been reported (4) compared with lifetime prevalence estimates for other anxiety disorders of $6 \%$ for generalized anxiety disorder, 5\% for panic disorder, $7 \%$ for post-traumatic stress disorder (PTSD) and $2 \%$ for obsessive-compulsive disorder (OCD). Twelve-month prevalence rates as high as $7 \%$ have been reported for social anxiety disorder (ㄷ). Using strict criteria and face-to-face interviews in the US, the lifetime and yearly prevalence figures are halved to $5 \%$ and $3 \%$, respectively (ㅁ), but it is still more common than the major autoimmune conditions (rheumatoid arthritis, ulcerative colitis, Crohn's disease, systemic lupus erythematosus, diabetes mellitus type I, multiple sclerosis, uveitis, hypothyroidism and hyperthyroidism) put together ( $\underline{8}$ ). Data from the National Comorbidity Survey reveals that social anxiety disorder is the third most common psychiatric condition after major depression and alcohol dependence

Methods our survey study was done in baha region and covered 6 cities(Baha,Qara,Mandaq,Bulgurashi,Aqaq and $\mathrm{M}$ ekhwah)all of them are belonging to al Baha region, 31 schools and 1316 students the sample taken was 1030 students. 5 of them did not complete the research. We used 2 tools of diagnosis:

1. Rewitie scale

2. Severity measure for social anxiety disorder

The team work distribute the scales to the students in their schools under the team supervision there was a paper of demographic data as a cover of the scales including an approval item which target to know if the student agree to answer the scales or not in this paper there were some questions about the possible risk factors for further researches .these questions include the presence or absence of the parents ,history of using any addictive drugs or history of dependence and presence of any organic or psychiatric problems the study included both sexes. the study began at 14/5/2017 and ended at 22/6/2018 the team work visited each school after the coordinator got the approval from the responsible in the educational institute the team work visited every class room separately in each school which were 31 schools distributed in 6 cities in baha region and explain to the students each scale and how to answer the questions. the students were allowed to take their time to answer the scales under the team work supervision . severity scale of social anxiety include 10 questions .therewitie scale cover 3 dimensions of social anxiety(interacting with others, dealing with social situations and its avoidance and physiological symptoms during social situations ). After collecting the scales the team work correct it to gather the data to conclude the results .

\section{Results:-}

The student mean age was 15.4 years with a standard deviation (SD of 2.1 years). About 96.4 of them were Saudi . More than one- third (39.2\%) were in grade one while $35.12 \%$ and $25.7 \%$ were in grades two and three, respectively. (81.26.3\%) had parents living together. Family size ranged between 6 and 10 was the major size $56.09 \%$, the first birth order was then major $(36.78 \%)$. Place of living divided between rural and urban areas $(50.6 \%$ \& $49.4 \%)$ respectively . (86.73 of the parents was free from physical illness and $2.34 \%$ had a psychiatric illness. table (1)

Shape (1) distribution of the sample and affected student according to cities . while table show demographic data and risk factors and differences between healthy group and social anxiety group in which the birth order and place of the residence Had a significant difference ( $p$ value were less than 0.001)

\section{prevalence and grade of social phobia}

Among secondary school students. The prevalence of social anxiety was $21.8 \%$. according the Rewitie scale the most prominent symptoms was to be silent in social situation and avoidance the situation while the least symptom was loss of consciousness . the mean and standard deviation for severity index was $(0.60 \pm 0.64)$. The prevalence of severe and moderate form was $10.5 .1 \%, 25.4 \%$ respectively. table (2)

Association of potential socio- demographic risk factors and social phobia was analysed. None of the potential socio- demographic factors (age of the students, Grade of school, family size, parental status, family size, , gender, and physical and mental state of the parents) except birth order and place of residence were found to be significantly associated with social phobia. $(\mathrm{OR}=3.97,95 \% \mathrm{CI}: 1.90-8.31$ and $\mathrm{OR}=2.67,95 \%$ CI: $3.17-5.19$, respectively. Table(3) 
Table 1:-show sociodemographic data of the sample.

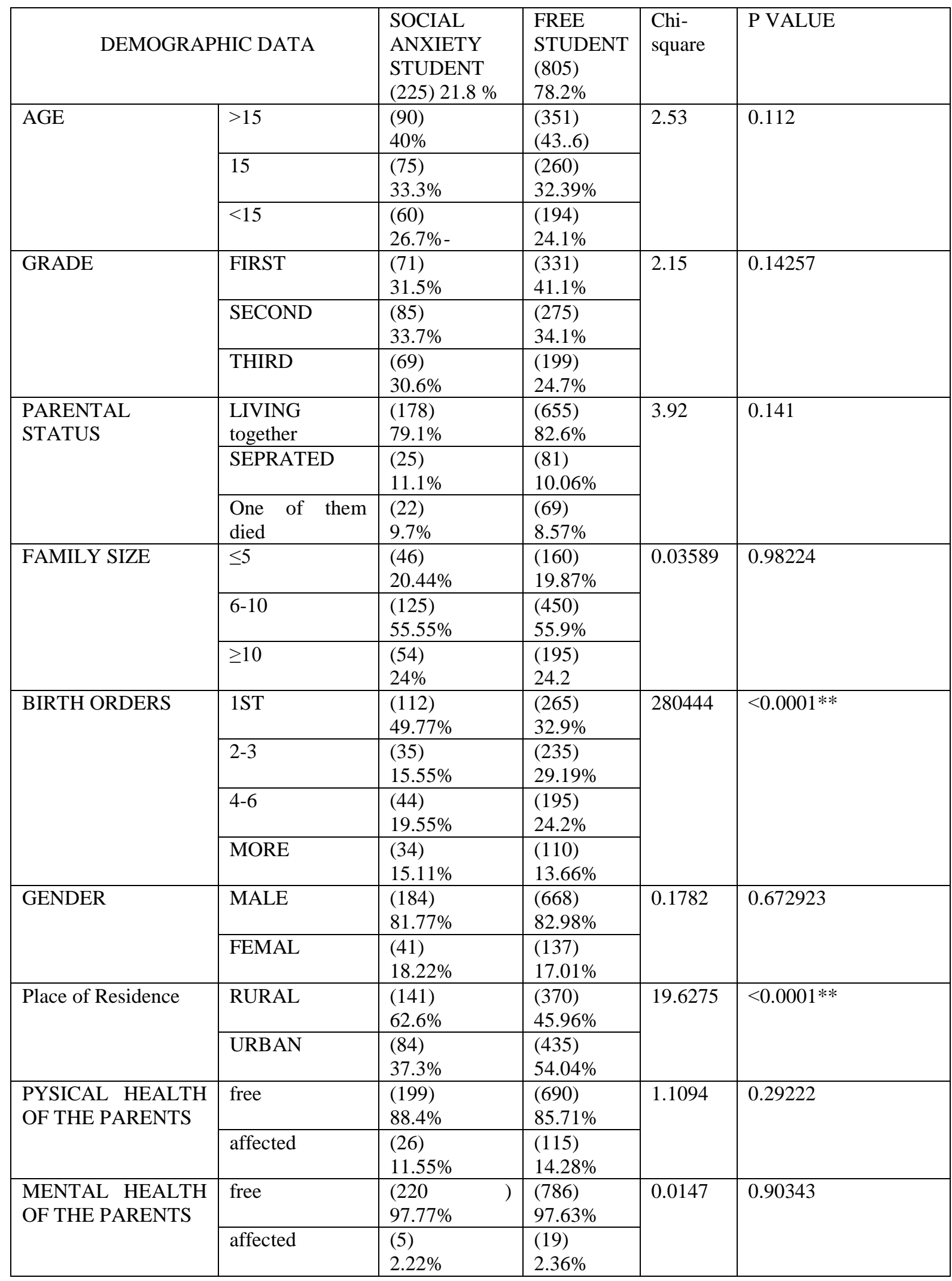




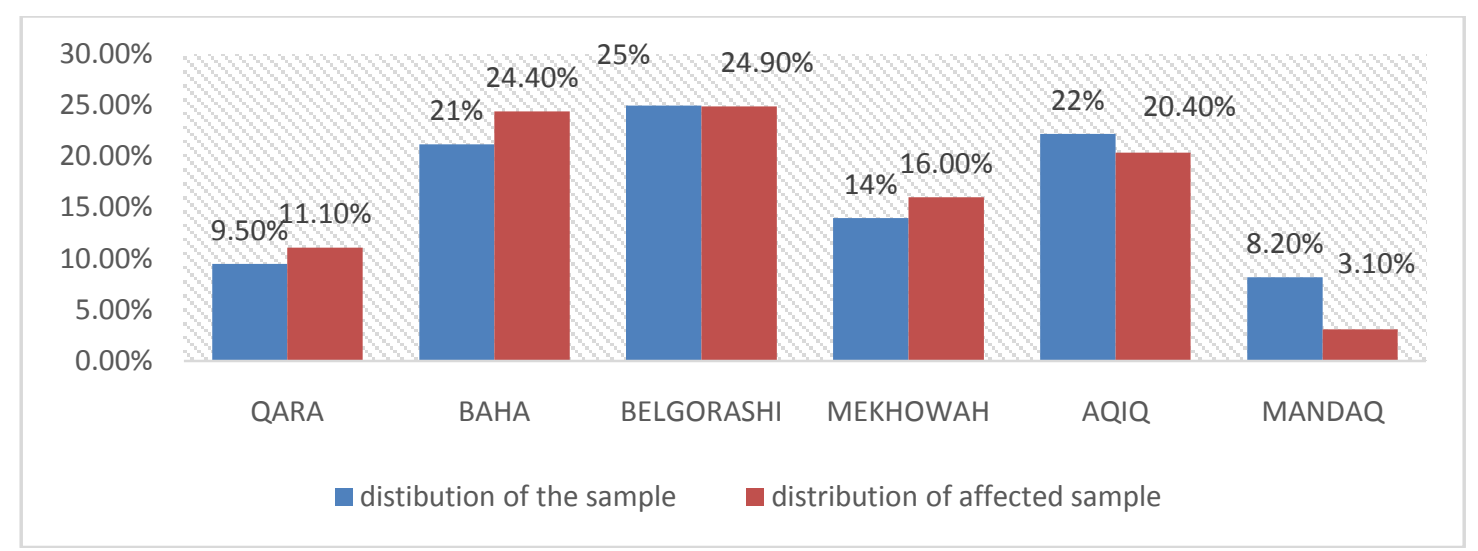

Shape 1:-distribution of the sample and affected student according to cities

Table 2:-distribution of the sample according to severity and rewitie scale

\begin{tabular}{|l|l|c|}
\hline & Range & $\begin{array}{l}\text { Mean } \pm \text { standard } \\
\text { deviation }\end{array}$ \\
\hline Severity scale & $0.0-4.0$ & $0.60 \pm 0.64$ \\
\hline Rewtie scale & $0.0-189.0$ & $26.66 \pm 26.0$ \\
\hline
\end{tabular}

Table 3:-Logistic regression analysis independent predictors of social anxiety disorder among secondary school students

\begin{tabular}{|l|l|l|l|}
\hline Predictor & $\boldsymbol{\beta}$ & $\boldsymbol{p}$-value & OR (95\% CI) \\
\hline Birth order & 1.38 & 0.0001 & $3.97(1.90-8.31)$ \\
\hline Place of Residence & 0.98 & & \\
\hline
\end{tabular}

\section{Discussion}

This is the first study that estimate the prevalence of social anxiety disorder in al Baha region . the team work aimed to conclude data that can be used in other researches and also can be used for measurement of the problem . having these data detect the size of the problem and give an impression about its significance the study gave us a variatition of the percentage among the 6 cities what is mean that there are a lot of factors that play a role in this variation . the prevalence of social anxiety disorders was was found to be $21.8 \%$. this is more than the results of some international studies that showed lifetime estimates for SAD as $8-12 \%$. and less than some Saudi study which estimate a higher prevalence $(16.4 \%$ ) [The suspected reason could be increase the number of female participants in this study and females are more likely to suffer from this disorder as documented.[8.9.10]

\section{Risk factors}

The current study showed that there is highly statistically significant difference between birth order and social anxiety which is consistent with Risal and Tharuur [11] who stated that there are associations between birth order and various forms of psychopathology including anxiety and depression . the firstborn child also appear to be more neurotic in the sense of being temperamental and anxious about their status.(10)

The current study showed a statistically significant difference between the place of residence and students' level of anxiety while there is highly statistically significant difference between place of residence and social anxiety. This might be due culture effect in the rural areas is so restricted and controlled by rigid discipline .

The current study showed that there is no statistically significant difference between other sociodemographic factor or risk factors ( age , gender ,number of family member and mental and physical state of the parents which is constant with some Saudi studies. (12.13.14.15)

At the end this study is considered a start for more and more researches to reach to other risk factors including the environmental factors that has its obvious smell in the results .especially social anxiety has its effect in society that 
can interfere with youth production and leave its passive power among people and Loosing youth power ,creativeness , sociability, production which will affect all levels of financial situation.

\section{Conclusion:-}

There is a high percentage of secondary school students diagnosed with social anxiety disorder (using the mentioned scales) showing the importance of the problem in Baha region for further researches behind the causes

\section{Conflicts of Interest}

the authors declare that there is no conflict of interest regarding the publication of this paper.

\section{Funding Statement}

We did not receive any fund.

\section{Data Availability Statement}

All data are available upon request.

\section{References:-}

1. Marks, I. M., \& Gelder, H. G. (1965). A controlled retrospective study of behavior therapy in phobic patients. The British Journal of Psychiatry, 111(476), 561-573.

2. World Health Organization. (1993). The ICD-10 classification of mental and behaviouraldisorders : diagnostic criteria for research. Geneva : World Health Organization. http://www.who.int/iris/handle/10665/37108.

3. American Psychiatric Association. (2000). Diagnostic and statistical manual of mental disorders, (4th ed., text revision). Washington, DC: American Psychiatric Association.

4. Kessler RC, Berglund P, Demler O, Jin R, Merikangas KR, Walters EE. (2005a) Lifetime prevalence and ageof-onset distributions of DSM-IV disorders in the National Comorbidity Survey Replication. Archives of General Psychiatry. ;62(6):593-602. DOI: 10.1001/archpsyc.62.6.593. [PubMed]

5. Kessler RC, Chiu WT, Demler O, Merikangas KR, Walters EE. (2005b) Prevalence, severity, and comorbidity of 12-month DSM-IV disorders in the National Comorbidity Survey Replication. Archives of General Psychiatry. ;62(6):617-627. DOI: 10.1001/archpsyc.62.6.617.

6. Grant BF, Hasin DS, Blanco C, Stinson FS, Chou SP, Goldstein RB, et al. The epidemiology of social anxiety disorder in the United States: (2005) Results from the National Epidemiologic Survey on Alcohol and Related Conditions. J Clin Psychiatry [Internet].;66(11):1351-61.

7. Fehm L, Wittchen HU. 2004. Comorbidity in social anxiety disorder., Stein DJ, editors. Social Anxiety Disorder. New York: Marcel Dekker; p. 49- 63.9.

8. Katzman MA, Bleau P, Blier P, Chokka P, Kjernisted K, et al., (2014) Canadian Anxiety Guidelines Initiative Group on Behalf of the Anxiety Disorders Association of Canada/Association Canadienne des Troubles Anxieux and McGill University, et al. Canadian clinical practice guidelines for the management of anxiety, posttraumatic stress and obsessive- compulsive disorders. BMC Psychiatry;14 Suppl 1:S1.

9. Pélissolo A, Huron C, Fanget F, Servant D, Stiti S, Richard- Berthe C, et al. (2006 ) Clinical and therapeutic characteristics of social phobia in French psychiatry (Phoenix study). Encephale;32 (1 Pt 1):106- 12.

10. Fehm L, Pelissolo A, Furmark T, Wittchen HU. ( 2005) Size and burden of social phobia in Europe. Eur europsychopharmacol.;15:453- 62 .

11. Risal, A. and Tharoor, H. (2012). Birth Order and Psychopathology, Original Article, Volume: 1 , Issue: 2 , 137-140.

12. Al- Gelban KS. (2007 ) Depression, anxiety and stress among Saudi adolescent school boys. J R Soc PromotHealth;127:33- 7.

13. Mahfouz AA, Al- Gelban KS, Al Amri H, Khan MY, Abdelmoneim I, Daffalla AA, et al. (2009) Adolescents' mental health in Abha city, southwestern Saudi Arabia. Int J Psychiatry Med;39:169- 77.

14. Abdel- Fattah MM, Asal AM, Al- Asmary SM, Al- Helali NS, Al- Jabban TM, et al.,. (2004) Emotional and behavioral problems among male Saudi schoolchildren and adolescents prevalence and risk factors. Ger $\mathbf{J}$ Psychiatry; $1: 1-9$.

15. Bassiony MM. (2005) Social anxiety disorder and depression in Saudi Arabia. Depress Anxiety;21:90-4. 